\title{
Towards an Understanding Business Intelligence. A Dynamic Capability-Based Framework for Business Intelligence
}

\author{
Celina M. Olszak \\ Katowice University of Economics \\ ul. Bogucicka 3b, \\ 40-287 Katowice, Poland \\ Email: celina.olszak@ue.katowice.pl
}

\begin{abstract}
Although Business Intelligence (BI) is one of the most essential technologies to be purchased, the implementation of many BI applications fails. The reasons for this failure are not clear and still not well investigated. Resource-based View (RBV) and dynamic capability theory could help to overcome this gap and to provide an appropriate theoretical basis for future research in BI area. It is considered that BI capabilities may be critical functionalities that help organizations to improve their performance and adopt to environmental change. The research objectives for this study are: (1) conceptualization and discussion on BI dynamic capability, (2) building the comprehensive framework of BI capabilities. In order to address these objectives, the remainder of the paper is structured as follows: The first sections provide the theoretical foundations of $\mathrm{BI}, \mathrm{RBV}$ and dynamic capability theory. Next, the BI capability was conceptualized. Finally, a model of BI as a dynamic capability, was proposed. The study was based mainly on: (1) a critical analysis of literature, (2) an observation of different BI initiatives undertaken in various organizations, as well as on (3) interviews with managers and experts in BI. The results of this study can be used by IT and business leaders as they plan and develop BI capabilities in their organizations.
\end{abstract}

\section{INTRODUCTION}

$\mathrm{I}_{\mathrm{org}}^{\mathrm{N}}$ $\mathrm{N}$ order to gain competitive advantage, many organizations decide to use Business Intelligence (BI) systems. It is believed that BI enables organizations to better understand not only internal business processes, but also the competitive environment through the systematic acquisition, collation, analysis, interpretation and exploitation of information. BI allows for the identification of the opportunities and threats, which may occur on the market, while cooperating with customers, suppliers and competitors [1], [2], [3], [4], [5], [6], [7], [8].

It is worth mentioning, that in 2010, BI topped the list of the most important application and technology development in an annual survey of IT executives [9]. According to Gartner research and Forrester the BI market will grow from $\$ 8,5$ billion in 2008 to $\$ 12$ billion in 2014 [10]. Although BI is one of the most essential technologies to be purchased, many BI applications fail or the organizations do not achieve the appropriate benefits [11], [12], [13], [14], [15]. The reasons for this failure are not clear and still not well investigated. Resource-based View (RBV) and dynamic capability theory could help to overcome this gap and to provide an appropriate theoretical basis for future research in BI area.
This paper seeks to throw more light on the concept of BI by using a dynamic capabilities perspective. I consider that BI capabilities may be critical functionalities that help organizations to improve their performance and adopt to environmental change.

The research question I ask in this paper is: what new light contribute RBV and dynamics capabilities to BI area. Consequently, the research objectives for this study are: (1) conceptualization and discussion on BI dynamic capability (2) building a comprehensive framework of dynamic capabilities for BI.

In order to address these objectives, the remainder of the paper is structured as follows: The first sections provide the theoretical foundations of BI, RBV and dynamic capability theory. Next, the BI capability was conceptualized. Finally, a comprehensive framework of BI as a dynamic capability was proposed. The study was based mainly on: (1) a critical analysis of literature, (2) an observation of different BI initiatives undertaken in various organizations, as well as on (3) interviews with managers and experts in BI. The results of this study can be used by IT and business leaders as they plan and develop BI capabilities in their organizations.

\section{BACKGROUND ON BUSINESS INTELLIGENCE AND DYNAMIC CAPABILITIES}

\section{A. Business Intelligence}

Business Intelligence has become the significant research area in the domain of management information systems in the last years. The roots of BI originate from decision support systems, which first emerged in the early 1970s when managers used computer applications to model business decisions. Over the years, other applications, such as executive information systems (EIS), online analytical processing (OLAP), data warehousing, and data mining became important [5],[6], [7]. Today BI is compared to "an umbrella" that is commonly used to describe the technologies, applications, and processes for gathering, storing, accessing and analyzing data to help users to make better decisions [1], [16].

$\mathrm{BI}$ is comprised of both technical and organizational elements [17], [18], [19], [20], [21]. From technical point of view $\mathrm{BI}$ is an integrated set of tools, technologies and software products that are used to collect heterogenic data 
from dispersed sources and then to integrate and analyze data to make them commonly available. The key BI technologies include: data warehousing, data mining and OLAP [22]. They are often called BI.1.0.

In the last years, new techniques, such as: web mining, opinion mining techniques, mobile mining techniques and semantic processing are applied in building BI systems They are focused on processing of semi-structured or unstructured data that originate mainly from Internet and social media. BI addressed for acquiring and processing data from web resources are named BI 2.0. In turn, BI 3.0 are responsible for collecting and analyzing data from various mobile devices [7], [24].

From organizational perspective, BI means a holistic and sophisticated approach to cross-organizational decision support [8], [11], [25]. Negash and Gray [3] argue that BI is responsible for transcription of data into information and knowledge. Also, it creates some environment for effective decision-making, business processes, strategic thinking, acting in organizations and taking the competitive advantage [26], [27], [28], [29], [30]. Many authors highlight that BI is predisposed to support decision-making on all levels of management [1], [3], [8], [31], [32]. On the strategic level, with the help of $\mathrm{BI}$ it is possible to set objectives precisely and follow the realization of such established objectives. BI allows for performing different comparative reports, e.g. on historical results, profitability of particular offers, effectiveness of distribution channels or forecasting future results on the basis of some assumptions. On the tactical level BI may provide some basis for decision-making within marketing, sales, finance, capital management etc. BI allows for optimizing future actions and modifying organizational, financial or technological aspects of company performance appropriately in order to help enterprises to realize their strategic objectives more effectively. In turn, on the operational level, BI systems are used to perform ad hoc analyses and answer questions related to departments' ongoing operations, up-to-date financial standing, sales and co-operation with suppliers, customers [22].

It is indicated that BI facilitates the realization of business objectives through reporting of data to analyse trends, creating predictive models for forecasting and optimizing process for enhanced performance. The value of BI systems for business is predominantly expressed in the fact that such systems cast some light on information that may serve as the basis for carrying out fundamental changes in a particular enterprise. It is stated that BI has become the critical component for the success of the contemporary organization [2], [15], [33], [34]. Wells [18] argues that BI is the "capability of an organization to explain, plan, predict, solve problems, think in an abstract way, understand, invent, and learn in order to increase organizational knowledge, provide information for the decision-making process, enable effective actions, and support establishing and achieving business goals".

It should be pointed that although, BI applications have become the most essential technologies to be purchased in the last years, the BI success is still questionable. It is reported that the practical benefits from BI are often unclear and some organizations fail completely in their BI approach or they do not achieve the appropriate benefits [11], [12], [13], [14], [15]. It is said that about 60 to $70 \%$ of business intelligence applications fail due to the technology, organizational, cultural and infrastructure issues [35], [36], [37], [38]. It is reported that the most important elements that decide on BI success in the organizations include: quality of data and used technologies, skills, sponsorship, alignment between BI and business, and BI use [35]. Other elements concern: organizational culture, information requirements, and politics. According to Olszak and Ziemba [38] the biggest barriers that the organizations encounter during the implementation of BI systems have a business and organizational character. Among the business barriers, the most frequently mentioned are: the lack of well defined business problem, not determining the expectation of BI and the lack of relations between business and BI vision system. Whereas as the key organizational barriers the enterprises enumerate: the lack of manager's supporting, the lack of knowledge about the BI system and its capabilities, exceeded the BI implementation budget, ineffective BI project management and complicated BI project, the lack of user training and support.

\section{B. Resource-based View}

RBV argues that about the success of organization's strategy decide the configuration of its resources and capabilities that are the basis to build key competences. Acquiring, configuration, reconfiguration and developing of available resources is critical factor for taking the competitive advantage and creating the value [39], [40], [41].

RBV was put forward by Wernerfelt [42] and subsequently popularized by Barney's work [39]. Many authors made significant contribution to its conceptual development [43], [44], [45].

According to RBV in order to provide sustainable competitive advantage, resources should be (VRIN): Valuable (enable an organization to implement a valuecreating strategy), Rare (are in short supply), Inimitable (cannot be perfectly duplicated by rivals) and Nonsubstitutable (cannot be countered by a competitor with a substitute). In an extended approach of RBV resources imply intangible categories including organizational, human and networks [46]. This knowledge-based resource approach of RBV encourages organizations to obtain, access, and maintain intangible endowments because these resources are the ways in which firms combine and transform tangible input resources and assets [47]. It is reported that BI technology, as well others ICT, do not satisfy the VRIN criteria [48]. However, they may be synergistically combined with existing organizational resources, to form other VRIN resources [41], [49].

\section{Dynamic capabilities theory}

The concept of dynamic capabilities is rooted in the RBV of competitive advantage. RBV defines capability as the ability of a bundle of resources to perform an activity. It is a 
way of combining assets, people and processes to transform inputs into output [50].

Teece et al. [50] define capabilities as "the key role of strategic management in appropriately adapting, integrating, and reconfiguring internal and external organizational skills, resources, and functional competences to match the requirements of a changing environment". Many authors, explaining the topic of capabilities, highlight some differences between competency, capability and capacity [51]. Competence is the quality or state of being functionally adequate or having sufficient knowledge, strength and skill. While capability is a feature, faculty or process that can be developed or improved. Capability is a collaborative process that can be deployed and through which individual competences can be applied and exploited. Capacity is the power to hold, receive or accommodate.

Hamel and Prahalad [52] coined the term core competence to distinguish those capabilities fundamental to a firm's performance and strategy. Core competencies are the activities that the firm performs especially well compared to competitors and through which the firm adds value to its goods and services over a long period of time. They emerge over time through an organizational process of accumulating and learning how to deploy organizational resources and capabilities.

The RBV conceptualizes organizational resources as static, neglecting changes due to turbulent environments. A stable resource configuration can not guarantee long-term competitive advantage as organizations have to adopt this configuration to the market environment [50]. This argument is even stronger in dynamic market environments where there is "rapid change in technology and market forces and feedback effects on firms [53]. Dynamic capabilities were conceptualized in response to this criticism [41], [44].

Teece et al. [50] identify dynamic capabilities as "the firm's ability to integrate, build, and reconfigure internal and external competences to address rapidly changing environments". The notion of dynamic capabilities was subsequently refined and expanded [44], [45], [54]. Zollo and Winter [45] also distinguish dynamic capabilities from operational or ordinary capabilities. Operational capabilities enable firms to perform their every day living, "and while dynamic (as all processes are), they are used to maintain the status quo" [54]. By contrast, dynamic capabilities are those that enable a firm to constantly renew its operational capabilities and therefore achieve long-term competitive advantage.

It is worth noting, that RBV has been used extensively in IS (Information Systems) research to explain how IT (Information Technology) assets provide value and sustainable competitive advantage to organizations [41]. Some studies found a direct link between IT assets and value but most found that IS capabilities and the interaction of IT assets with other organizational resources, lead to business value [40], [41]. IS capabilities are created through combining IT assets with other resources including people, routines and processes. IS capabilities develop and mature over time as organizational learn [43]. Dynamic capabilities are the high-order capabilities and thus can be disaggregated into different capacities, such as the capacity for improving quality, the capacity for managing human resources and the capacity for utilizing technologies [55].

\section{Conceptualization of dynamic Business Intelligence capabilities}

Drawn from the concept of dynamic capabilities, BI capability may be defined as IT-enabled, analytical dynamic capability for improving decision making and firm's performance [55]. It is a specific and important type of IS capabilities. Different organizational characteristics and strategic goals may also require using different BI capabilities. According to Gartner Group BI capabilities relate to information access and analysis to decision-making style within an organization [11]. Isik, Jones and Sidorova [11] delineate information access and analysis capabilities and relate them to the overall BI success. Davenport and Harris [6] state that analytical capability is a key element of strategy for the business. Wixom, Watson and Werner [5] argue that BI capability is "a journey over long periods of time during which foundational competencies are developed".

According to Teece et al. [50] dynamic capabilities can be distinguished into three classes of activities including sensing, seizing, and transformation. In the context of Business Process Management [53] and also of BI, sensing refers mainly to identification of the need to change an organization's business processes, relations with customers and suppliers. Seizing means the exploration and selection of opportunities for change. Transformation concerns sociotechnically implementation of changed business processes in the organization. Some authors argue that BI capabilities are critical functionalities of BI that help an organization to improve its adoption to change as well as to improve its performance [5], [11].

Organizations may develop two activities in order to build BI capability. The former concerns the widely understood data exploration, the latter, data exploitation [56]. Data exploration enables organization to overcome the bounder of actual knowledge and its capabilities. This may refer to new technical capabilities, market experiences and new relations with the environment. Also, the exploration is a conscious searching of new knowledge sources, enriching of existing resources, adoption of new behavioral orientations and acquisition of new competencies. It can be achieved through: advances data mining, text mining, web mining, intelligent agents, and search based application. In turn, data exploitation concerns the using of existing knowledge bases. It is limited to actual resources and refers to their detail analysis.

Davenport and Harris [6] distinguish five stages of analytical capability called: analytically impaired, localized analytics, analytical aspiration, analytical companies, and analytical competitors. The first stage means that "organizations have some desire to become more analytical, but thus far they lack both the will and the skill to do so". They face some substantial barriers - both human and 
technical. They may also lack the hardware, software and skills to do substantial analysis. The second stage "localized analytics " is characterized by reporting with pockets of analytical activity. The organizations undertake the first analytical activities, but they have no intention of competing on it. BI activities produce economic benefits but not enough to affect the company competitive strategy. The third stage called "analytical aspirations" is triggered when BI activities gain executive sponsorship. The organizations build the plan of using BI. The primary focus in "analytical companies" stage is building word-class analytical capabilities at the enterprise level. The organizations implement the plan developed in previous stage, making considerable progress toward building the sponsorship, culture, skills, strategic insights, data and technology needed for analytical competition. At the last stage, analytics moves from being a very important capability for an organizations to the key to its strategy and competitive advantage. Executive managers trust in BI and all users are highly educated in BI.

For the purpose of this paper it is assumed that dynamic BI capability is the ability of an organization to integrate, build and reconfigure the information resources, as well as business processes to address rapidly changing environments.

\section{RESEARCH METHODOLOGY}

An interpretative philosophy and an inductive qualitative approach were applied to build a comprehensive, dynamic BI capabilities framework. The theories (from IS and management literature) and studies developed mainly by Davenport and Harris [6], Wixom, Watson, and Werner [5], Cosic, Shankes, and Maynard [41] were adopted and used to create the dynamic BI capabilities framework.

$\mathrm{BI}$ is regarded as an applied discipline and therefore practitioner, viewpoints and opinions were considered of high importance. Therefore, I have used the results from the survey that was conducted in 2012 among 20 purposefully selected firms (in Poland) that are considered to be advanced in BI [24]. They represented the service sector: telecommunications, consulting, banking, insurance, and marketing agencies. Interviews were held with executives, senior members of staff and ICT specialists. Interviewees were selected on their involvement in BI or on their ability to offer an insight based on experience in BI and related decision support systems. The research was of qualitative nature and used as a research technique of an in-depth interview. Types of core interviews questions relevant to this paper have included among others: (1) Does your organization have a defined BI strategy?, (2) Does your organization have defined business processes?, (3) Are you skilled enough in order to take advantage of BI systems?, (4) Are you motivated to use BI (how)?, (5) Do you use BI for analyzing customers, suppliers, competitors and other business partners?, (6) What kind of BI software do you use?, (7) Describe some successes/failures from using BI. This methodology is appropriate for the explorative objectives of this research as it aimed to build dynamic BI capabilities framework.

\section{FINDINGS AND DISCUSSION}

Figure 1 provides an initial framework for dynamic BI capabilities. It includes six capabilities areas like: governance, culture, technology, people, processes, and change management $\&$ creativity. So far, these areas were presented separately and were used for different aims and tasks. In this study, I integrate them into one comprehensive model for dynamic BI capabilities. Below, I present the arguments for adopting them to create a dynamic BI capability.

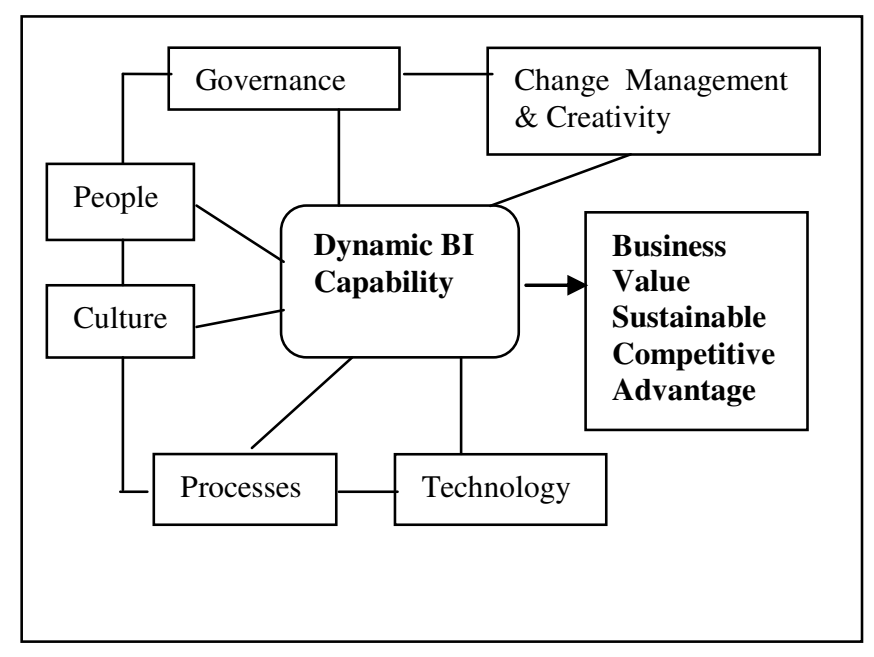

Fig. 1 Framework for BI capabilities

The governance is "the mechanism for managing the use of BI resources within an organizational and the assignment of BI initiatives with organizational objectives. It also involves continuously renewing BI resources and organizational capabilities in order to respond to changes in dynamic environments and mitigating resistance to change" [41].

Culture is often described as "personality of the organization" and comprises the assumptions, values, norms, and behavioral signs of organization/s members. They form over time and lead to systematic ways of gathering, analyzing and disseminating data. It influences the way decisions are made [41].

People refer to "all those individuals within organization who use BI as part of their job function. BI initiatives are considered to be knowledge intensive and require technical, business, managerial and entrepreneurial skills and knowledge" [41].

Technology refers "to the development and use of hardware, software and data within BI activities. It includes the management of an integrated and high quality data resources, the seamless integration of BI systems with other organizational information systems, the conversion of data into information through reporting and visualization systems and to use of more advanced statistical analysis tools to discover patterns, predict trends and optimize business process" [41]. 
Process constitutes of activities to gather, select, aggregate, analyze, and distribute information. Some of these activities are the responsibility of the BI staff, while others are the joint responsibility of the BI staff and the business units. Processes may be divided into categories: internal and external processes. The first group relates mainly to accounting, finance, manufacturing, and human resources. The second group concerns managing and responding to customer demand and supplier relationships [6].

Change management \& creativity are organization's abilities to meet the requirements of dynamic environments. Organizations face rapid change like never before. Therefore, the ability to manage and adapt to organizational change is an essential ability required in the workplace

today. Change management is an approach to transitioning individuals, teams, and organizations to a desired future state. BI requires permanent development and adaptation to new challenges and expectations of an organizations. While an organizational creativity is the firm's ability to generate new and useful ideas to address rapidly changing opportunities and threats by making timely and marketoriented decisions, and to frame breaking changes in its resource base.

The essentials analysis of the literature and the conducted interviews with various BI experts and managers allowed me to identify the detailed capabilities for each BI area (table 1). The number of the organizations that declared the possession of various BI capabilities and competences is presented in the last column of the table.

Table I.

BI CAPABILITIES AREA

\begin{tabular}{|c|c|c|}
\hline BI Capabilities Area & Detailed BI capabilities & Number of organizations \\
\hline Governance & $\begin{array}{l}\text { Business vision and plan } \\
\text { Business analysis planning and monitoring } \\
\text { Strategic alignment BI and business strategy } \\
\text { Decision rights (operational, tactical, strategic) } \\
\text { BI solution assessment and validation }\end{array}$ & $\begin{array}{r}10 \\
11 \\
5 \\
16 \\
7\end{array}$ \\
\hline Culture & $\begin{array}{l}\text { Executive leadership and support } \\
\text { Flexibility and agility } \\
\text { Establishing a fact-based and learning culture }\end{array}$ & $\begin{array}{l}6 \\
8 \\
7\end{array}$ \\
\hline Technology & $\begin{array}{l}\text { Data management } \\
\text { Systems integration and interaction with other systems } \\
\text { Flexibility } \\
\text { Reporting and visualization technology } \\
\text { Advanced BI technology (OLAP, data warehousing, data mining, predictive analysis) }\end{array}$ & $\begin{array}{l}16 \\
17 \\
17 \\
20 \\
16\end{array}$ \\
\hline People & $\begin{array}{l}\text { Securing and building technology skills } \\
\text { Mathematical and statistical skills } \\
\text { Organizational skills } \\
\text { Organizational knowledge, knowledge sharing } \\
\text { Managing analytical people } \\
\text { Business interpersonal communication } \\
\text { Entrepreneurship and innovation } \\
\text { Trustworthiness }\end{array}$ & $\begin{array}{c}7 \\
5 \\
7 \\
5 \\
6 \\
12 \\
5 \\
6 \\
\end{array}$ \\
\hline Process & $\begin{array}{l}\text { Holistic overview business process/ knowledge processes } \\
\text { Business process/knowledge/ modeling and orchestration } \\
\text { Process redesign and integration }\end{array}$ & $\begin{array}{l}14 / 7 \\
16 / 6 \\
16\end{array}$ \\
\hline Change \& Creativity & $\begin{array}{l}\text { Monitoring of competitors, customers and current trends in the marketplace } \\
\text { Introducing new business models oriented on change management, knowledge } \\
\text { management and customer relationship management } \\
\text { Generation of new and useful products, services, ideas, procedures, and processes }\end{array}$ & $\begin{array}{l}9 \\
7 \\
7\end{array}$ \\
\hline
\end{tabular}

In the next step of my research, five detailed BI capabilities areas were mapped onto Davenport and Harris model. As a the result, a BI capabilities maturity matrix was created (table 2).

The analysis of the literature and the conducted survey allow me to state that the dynamic BI capabilities do not go hand in hand with the possibilities offered by BI technologies. Most organizations need to raise their "analytical erudition." Managers do not always know how such sources can be used in making decisions. The most of the organizations do not think creatively about the potential of data sources. They have a relatively high level of the technical competences. Unfortunately, they do not correspond with another BI capabilities (e.g., strategic alignment BI and business strategy, establishing a fact-based and learning culture, entrepreneurship and innovation, change management, and creativity).

$\mathrm{BI}$ is still treated as a technology or tool to acquire and analyze data and not as a trigger for making more effective decisions, improving business processes and business performance, as well as doing new business or creating new ideas and procedures. The organizations still underestimate the soft competences and skills needed for BI (e.g., culturebased on facts and knowledge, trust, human resources management, managing analytical/creativity people). Worried, that BI and business strategy are not aligned in many organizations. 
Table II.

BI CAPABILITIES MATURITY MATRIX

\begin{tabular}{|c|c|c|c|c|c|}
\hline $\begin{array}{l}\text { BI } \\
\text { capabilities } \\
\text { area }\end{array}$ & $\begin{array}{l}\text { Analytically } \\
\text { impaired }\end{array}$ & Localized analytics & Analytical aspiration & Analytical companies & Analytical competitors \\
\hline Governance & $\begin{array}{l}\text { Lack of vision and } \\
\text { plan }\end{array}$ & $\begin{array}{l}\text { Businesses plans for } \\
\text { limited departments }\end{array}$ & $\begin{array}{l}\text { Integrated business } \\
\text { strategy }\end{array}$ & $\begin{array}{l}\text { Have an enterprise BI } \\
\text { strategy }\end{array}$ & $\begin{array}{l}\text { BI strategy oriented on } \\
\text { customers, suppliers etc. }\end{array}$ \\
\hline Culture & $\begin{array}{l}\text { No flexibility and } \\
\text { agility }\end{array}$ & $\begin{array}{l}\text { Low support from } \\
\text { senior executives }\end{array}$ & $\begin{array}{l}\text { Users are encouraged to } \\
\text { collect, process analyze } \\
\text { and share information }\end{array}$ & $\begin{array}{l}\text { Establishing a fact-based } \\
\text { and learning culture, skill } \\
\text { training in BI }\end{array}$ & $\begin{array}{l}\text { Learning from customers, } \\
\text { suppliers, communities of } \\
\text { practice, social media }\end{array}$ \\
\hline Technology & $\begin{array}{l}\text { Missing/poor data, } \\
\text { Unintegrated } \\
\text { systems }\end{array}$ & $\begin{array}{lrr}\text { Missing } & \text { important } \\
\text { data, } & \text { Isolated } & \text { BI } \\
\text { efforts } & & \\
\end{array}$ & Proliferation of BI tools & $\begin{array}{l}\text { High- quality of data, } \\
\text { integrated knowledge } \\
\text { repositories }\end{array}$ & $\begin{array}{lr}\begin{array}{l}\text { Enterprise-wide } \\
\text { architecture }\end{array} & \mathrm{BI} \\
\text { implemented } & \text { largely } \\
\end{array}$ \\
\hline People & $\begin{array}{l}\text { Users do not know } \\
\text { their own data } \\
\text { requirements or how } \\
\text { to use them }\end{array}$ & $\begin{array}{l}\text { The users take the first } \\
\text { BI initiatives }\end{array}$ & $\begin{array}{l}\text { Users try to optimize the } \\
\text { efficiency of individual } \\
\text { departments by BI }\end{array}$ & $\begin{array}{l}\text { Users have high BI } \\
\text { capabilities, but often not } \\
\text { aligned with right role }\end{array}$ & $\begin{array}{l}\text { Users have capabilities and } \\
\text { time to use BI }\end{array}$ \\
\hline Processes & $\begin{array}{l}\text { Users do not know } \\
\text { business processes }\end{array}$ & $\begin{array}{l}\text { Identification of basic } \\
\text { business processes }\end{array}$ & $\begin{array}{l}\text { Standardization } \\
\text { business processes, and } \\
\text { building best practices } \\
\text { in BI }\end{array}$ & $\begin{array}{l}\text { Business process } \\
\text { management based on } \\
\text { facts }\end{array}$ & $\begin{array}{l}\text { Broadly supported, } \\
\text { process-oriented culture } \\
\text { based on facts }\end{array}$ \\
\hline $\begin{array}{ll}\text { Change } & \& \\
\text { Creativity } & \end{array}$ & $\begin{array}{l}\text { Fear of change, no } \\
\text { creativity }\end{array}$ & $\begin{array}{l}\text { Risk management for } \\
\text { selected business } \\
\text { process, poor and } \\
\text { limited creativity }\end{array}$ & $\begin{array}{l}\text { Building the best } \\
\text { practices for change } \\
\text { management, individual } \\
\text { and team creativity }\end{array}$ & $\begin{array}{l}\text { Integrated risk } \\
\text { management, team and } \\
\text { organizational creativity }\end{array}$ & $\begin{array}{l}\text { Cooperation with } \\
\text { competition, } \\
\text { organizational creativity, } \\
\text { creative environment }\end{array}$ \\
\hline
\end{tabular}

In order to reach a comprehensive, dynamic BI capability, organizations should simultaneously build and developed a whole bundle of various BI capabilities. Undoubtedly, it is a long journey and developed over long periods of time. I think, that organizations should not start from building technical competences, structures (data bases, data warehouses etc.), without prior the implementation of knowledge-based organization, change management, and organizational creativity.

Concluding, I consider that organizations should simultaneously develop different BI capabilities in order to achieve high BI maturity. These capabilities may be focused on data exploration and data exploitation. As mentioned earlier, data exploration enables organization to overcome the bounder of actual knowledge and its capabilities. In contrast, data exploitation concerns the using of existing knowledge bases. It is limited to actual resources and refers to their detail analysis. The adequate linking capabilities concerning exploration and exploitation of the knowledge are useful solution for organizations. This results from the rapid obsolescence of knowledge, shortening life cycle of many products and services. Therefore, it is important for the survival and success of the organization to maintain some balance between these activities.

\section{CONCLUSIONS}

The research propose of this study was to investigate how Resource-based View and dynamic capability theory may be adopted and used in BI area. It was illustrated that they through more light on our BI understanding. I have proposed a comprehensive, dynamic BI capabilities framework that reflects six BI capabilities areas: governance, culture, technology, people, processes and change $\&$ creativity. This dynamic capability framework suggests that the abilities needed depend highly on the dynamics of the environment.
The conducted survey has shown that BI is still treated as a technology or tool to acquire and analyze data and not as a trigger for making more effective decisions, improving business processes and business performance, as well as doing new business or creating new ideas and procedures. The organizations still underestimate the soft competences and skills needed for BI (e.g., culture-based on facts and knowledge, trust, human resources management, managing analytical/creativity people). Worried, that BI and business strategy are not aligned in many organizations.

I consider that the father development of BI in organizations will depend on how they will focus on strategic alignment BI and business strategy, establishing a fact-based and learning culture, entrepreneurship and innovation, change management, and creativity. The time of technical BI competences is over. Organizations should build a whole bundle of more soft BI capabilities.

Future research might take some of the following directions. It would be valuable to build holistic approach for building the dynamic BI capabilities. Further research might explore the detailed BI capabilities areas. Some empirical investigations and precise validations would be useful to explore the associations between BI capabilities and strategic orientations of the organizations.

\section{REFERENCES}

[1] T. H. Davenport, J. G. Harris, and R. Morison, Analytics at Work: Smarter Decisions, Better Results, Harvard Business Press, Cambridge, 2010.

[2] B.H. Wixom, and H.J. Watson, "The BI-based organization", International Journal of Business Intelligence Research, Vol. 1, No. 1, 2010, pp 13-28.

[3] S. Negash, and P. Gray, "Business Intelligence", in F. Burstein, and C.W. Holsapple (ed), Decision Support Systems, Springer, Berlin, 2008, pp 175-193. 
[4] B. Liautaud, and M. Hammond, E-Business Intelligence. Turning Information into Knowledge into Profit, McGraw-Hill, New York, 2002.

[5] B.H. Wixom, H.J. Watson, and T. Werner, "Developing an Enterprise Business Intelligence Capability: the Norfolk Southern Journey", MIS Quarterly Executive, Vol. 10, No.2, 2011, pp 61-71.

[6] T. H. Davenport, and J. G. Harris, Competing on Analytics. The New Science on Winning, Harvard Business School Press, Boston Massachusetts, 2007.

[7] H. Chen, R.H.L. Chiang, and V.C. Storey, "Business Intelligence and analytics: from Big data to big impact”, MIS Quarterly, Vol. 36, No. 4, 2012, pp. 1-24

[8] L. Moss, and S. Atre, Business Intelligence Roadmap: The Complete Lifecycle for Decision-Support Applications, Addison-Wesley, Boston, 2003.

[9] J. Lufman, and T. Ben-Zvit, "Key issues for IT executives 2009: difficult economy's impact on IT, MIS Quarterly Executive, Vol. 9, No 1, 2010, pp 203-213.

[10] Gartner, Gartner's 2011 CIO survey results, http://www.gartner.com/it/page.jsp?id=1526414.

[11] O. Isik, M. C. Jones, and A. Sidorova, "Business Intelligence (BI) Success and the Role of BI Capabilities", Intelligent Systems in Accounting, Finance and Management, Vol. 18, 2011, pp 161-176.

[12] H.J. Watson, B. Wixom, "Enterprise agility and mature BI capabilities”, Business Intelligence Journal, Vol. 12, No. 3, 2007, pp 4-6.

[13] S. Chaudhary, "Management factors for strategic BI success", in , M.S. Raisinghani (ed.), Business Intelligence in digital economy. Opportunities, limitations and risks, Hershey: IGI Global, 2004, pp 191-206.

[14] A. Schick, M. Frolick, and T. Ariyachandra, "Competing with BI and Analytics at Monster Worldwide", in Proceedings of the $44^{\text {th }}$ Hawaii International Conference on System Sciences, 2011.

[15] C. Howson, Successful Business Intelligence: Secrets to Making BI a Killer Application, McGraw-Hill, New York, 2008.

[16] H.J. Watson, SME performance: Separating myth from reality, Cheltenham: Edward Elgar Publishing, 2010.

[17] A. Alter, A work system view of DSS in its fourth decade, Decision Support System, Vol. 38, No. 3, 2004, pp 319-327.

[18] D. Wells, "Business analytics - getting the point", [online], http://beye-network.com/view/7133, 2008.

[19] Z. Jourdan, R. K. Rainer, and T. Marschall, "Business Intelligence: An Analysis of the Literature ", Information Systems Management, Vol. 25, No. 2, 2007, pp. 121-131

[20] W.W. Eckerson, The keys to enterprise Business Intelligence: critica success factors. The Data Warehousing Institute, 2005, Retrieved October $\quad 02$ from http://download.101com.com/pub/TDWI/Files/TDWIMonograph2BO.pdf.

[21] C.M. Olszak, and E. Ziemba, "Business Intelligence as a key to management of an enterprise", in E. Cohen, \& E. Boyd (ed.) Proceedings of Informing Science and IT Education InSITE'2003, Santa Rosa, The Informing Science Institute, 2003.

[22] C.M. Olszak, and E. Ziemba, E. "Business Intelligence systems in the holistic infrastructure development supporting decision-making in organizations", Interdisciplinary Journal of Information, Knowledge and Management, Vol. 1, 2006, pp 47-58.

[23] C.M. Olszak, and E. Ziemba, "Business Intelligence systems as a new generation of Decision Support Systems", in J.V. Carrasquero (ed.), Proceedings of PISTA 2004, International Conference on Politics and Information Systems: Technologies and Applications. Orlando: The International Institute of Informatics and Systemics, 2004

[24] C. M. Olszak, “Assessment of Business Intelligence Maturity in the Selected Organizations”, in: M. Ganzha, L. Maciaszek, M. Paprzycki (ed.), Annals for Computer Science and Information Systems, Vol. 1 2013, pp. 951-958, https://fedcsis.org/proceedings/2013/index.html.

[25] C. M. Olszak, "Business Intelligence as a key for the success of the organization", in M. Tvrdíková, J. Ministr (ed.), ICT for Practice, Ekonomicka Fakulta VSB-TU Ostrava, 2013, pp. 31-40.

[26] F. Albescu, I. Pugna, and D. Paraschiv, "Business Intelligence \& Knowledge Management - Technological Support for Strategic Management in the Knowledge Based Economy", Revista Informatica Economică, Vol. 4, No. 48, 2008, pp. 5-12.
[27] H. Baaras, and H.G. Kemper, "Management support with structured and unstructured data - an integrated Business Intelligence framework", Information Systems Management, Vol. 25, No. 2, 2008, pp. 132-148.

[28] W. Chung, H. Chen, and J.F. Nunamaker, "A visual framework for knowledge discovery on the web: An empirical study of business intelligence exploration", Journal of Management Information Systems Vol. 21, No. 4, 2005, pp. 57-84.

[29] P. Venter, and D. Tustin, "The availability and use of competitive and business intelligence in South African business organizations", South African Business Review, Vol. 13, No 2, 2009, pp. 88-115.

[30] C. M. Olszak, "The Business intelligence-based Organization- new chances and Possibilities", in V. Ribiere and L. Worasinchai (ed.), Proceedings of the International Conference on Management, Leadership and Governance, Bangkok University, Published by Academic Conferences and Publishing International Limited Reading, 2013, pp. 241-249.

[31] R. T. Herschel, and N.E. Jones, "Knowledge management and business intelligence: the importance of integration", Journal of Knowledge Management, Vol. 9, No. 4, 2005, pp. 45-54.

[32] J.J. McGonagle, and C.M. Vella, Bottom Line Competitive Intelligence, Quorum Books, Westport, CT, 2002.

[33] A. Weiss, "A brief guide to competitive intelligence", Business Information Review ,Vol. 19, No 2, 2002.

[34] S. Williams, N. Williams, The Profit Impact of Business Intelligence. Morgan Kaufmann, San Francisco, 2007.

[35] P. R. Clavier, H. Lotriet, and J. Loggerenberger, "Business Intelligence Challenges in the Context of Goods-and Service-Domain Logic", in $45^{\text {th }}$ Hawaii International Conference on System Science, IEEE Computer Society, 2012, pp. 4138-4147.

[36] M. Hannula, and V.Pirttimaki, "Business intelligence empirical study on the top 50 Finnish companies", Journal of American Academy of Business, Vol. 2, No. 2, 2003, pp. 593-599.

[37] A.J. Karim, "The value of Competitive Business Intelligence System (CBIS) to Stimulate Competitiveness in Global Market", International Journal of Business and Social Science, Special Issue, Vol. 2, No. 19, 2011, pp. 196-203.

[38] C. M. Olszak, and E. Ziemba, "Critical Success Factors for Implementing Business Intelligence Systems in Small and Medium Enterprises on the Example of Upper Silesia, Poland", Interdisciplinary Journal of Information, Knowledge, and Management, Vol. 7, 2012, pp.129-150. Informing Science Press, (http://www.ijikm.org/Volume7/IJIKMv7p129-150Olszak634.pdf)

[39] J. Barney, "Firm Resources and Sustained Competitive Advantage", Journal of Management, Vol. 17, No. 1, 1991, pp 99-120.

[40] M. Wade, and J. Hulland, "Review: The Resource-Based View and Information Systems Research: Review, Extension, and Suggestions for Future Research", MIS Quarterly, Vol. 28, No. 1, 2004, pp 1-25.

[41] R. Cosic, G. Shankes, and S. Maynard, "Towards a Business Analytical Capability Model", in $23^{\text {rd }}$ Australian Conference on Information Systems, Geelong, 2012.

[42] B. Wernfelt, "A Resource-based View of the Firm", Strategic Management Journal, Vol. 5, 1984, pp 171-180.

[43] J. Barney, M. Wright, and D.J. Kitchen, "The resource-based view of the firm: ten years after 1991", Journal of Management, Vol. 27, 1991, pp 625-641.

[44] K. M. Eisenhardt, and J.A. Martin, Dynamic Capabilities: What Are They? Strategic Management Journal, (2000), Vol. 21, No 10/11.

[45] M. Zollo, and S.G. Winter, "Deliberate Learning And The Evolution Of Dynamic Capabilities". Organization Science, 13(3), 2002, pp 339-351.

[46] M.J. Ahn, and A.S. York, "Resource-based and institution-based approaches to biotechnology industry development in Malaysia". Asia Pacific Journal of Management, Vol. 28, No. 2, 2011, pp 257 275.

[47] J. Wiklundi, D. Shepherd, "Knowledge-based resources, entrepreneurial orientation, and the performance of small and medium-sized businesses". Strategic Management Journal, Vol. 24, 2003, pp 1307-1314

[48] Gartner, "Magic Quadrant for Business Intelligence Platforms", Gartner Group, report G00210036.

[49] S. Nevo, and M. Wade, "The formation and Value of It-Enabled Resources: Antecedents and Consequences of Synergistic Relationship”, MIS Quarterly, Vol. 34, No. 1, pp 163-183. 
[50] D.J. Teece, G. Pisano, and A. Shuen, "Dynamic capabilities and strategic management", Strategic Management Journal, Vol. 18, No. 7, 1997, pp 509-533.

[51] L. Vincent, "Differentiating Competence, Capability and Capacity", Innovating Perspective, Vol. 16, No. 3, 2008, 460-1313, http://www.innovationsthatwork.com/images/pdf/June08newsltr.pdf

[52] C.K. Prahaland, and G. Hamel, The Core Competence of the Corporation, Harvard Business Review, May-June 1990.

[55] B.K. Chae, D.L. Olson, "Business Analytics for Supply Chain: A Dynamic-Capabilities Framework", International Journal of Information Technology \& Decision Making, Vol. 12, No. 1, 2013, pp 9-26.
[53] K. Ortbach, R. Plattfaut, J. Poppelbuss, B. Niehaves, "A Dynamic Capability-based Framework for Business Process Management: Theorizing and Empirical Application”, in $45^{\text {th }}$ Hawaii International Conference on System Sciences, IEEE, 2012, pp 4287-4296.

[54] C.E. Helfat, S. Finkelstein, W. Mitchell, M.A. Peteraf, H. Sing, D.J Teece, and S.G. Winter, Dynamic Capabilities Understanding Strategic Change in Organisations, Carlton: Blackwell, 2007.

[56] D. Lavie, U. Stettner, and M.L. Tushman (2010). "Exploration and Exploitation Within and Across Organizations", The Academy of Management Annals, Vo. 4, No. 1, 2010, pp 109-155.

\section{Acknowledgment}

This paper has been supported by a grant: „Methodology for Computer Supported Organizational Creativity” from National Science Centre in Poland, 2013/09B/HS4/00473. 